\title{
S.N. Fedosov, A.E. Sergeeva \\ Thin Films of Vinylidene Fluoride Copolymer with Tetrafluoroethylene: Dynamics of Ferroelectric Polarization Switching
}

\author{
Odessa National Academy of Food Technologies, Odessa, Ukraine, e-mail <snfedosov@ukr.net>
}

\begin{abstract}
The vinylidene fluoride copolymer with tetrafluoroethylene P(VDF-TFE) is a typical ferroelectric polymer that has not been sufficiently studied so far in comparison with pure polyvinylidene fluoride (PVDF) and its copolymer with trifluoroethylene. The purpose of this work was to reveal the features of forming ferroelectric polarization and its switching in thin films of $\mathrm{P}(\mathrm{VDF}-\mathrm{TFE})$ under various conditions, such as the level of the applied electric field and the duration of its action within 8 orders of magnitude from $10 \mu \mathrm{s}$ to $100 \mathrm{~s}$. The sequence of voltage pulses applied during poling and polarization reversal allowed to reveal the characteristics of the polarization switching dynamics. To increase the resolution of the measurements, two complementary methods of recording electrical induction were used. The features of polarization and space charge relaxation over time have been studied by thermally stimulated depolarization method. A new phenomenon of gradual separation of the relaxation processes associated with polarization and space charge was observed. Both components were accompanied by trapped charges that compensated the depolarizing field. Several practical recommendations have been formulated regarding the desirable values of poling parameters and additional processing to increase the ferroelectric polarization stability.
\end{abstract}

Key words: ferroelectrics, ferroelectric polymers, PVDF, P(VDF-TFE), polarization, electrets, space charge, thermally stimulated depolarization.

Received 02.02.2019; accepted for publication 15.03.2020.

\section{Introduction}

Ferroelectric polymers have the potential of application in electronic devices such as electroacoustic transducers, pressure and temperature sensors, and various detectors [1]. Typical ferroelectric polymers are polyvinylidene fluoride (PVDF) and its copolymers with tetrafluoroethylene P(VDF-TFE) and trifluoroethylene $\mathrm{P}(\mathrm{VDF}-\mathrm{TrFE})$. Ferroelectric polymers exhibit ferroelectric, piezoelectric and pyroelectric properties after a certain processing.

$\mathrm{P}(\mathrm{VDF}-\mathrm{TFE})$ is a linear polymer with tetrafluoroethylene $\left(\mathrm{C}_{2} \mathrm{~F}_{4}\right)$ units periodically inserted between vinylidene fluoride $\left(\mathrm{CF}_{2}-\mathrm{CH}_{2}\right)$ units. Lando and Doll pointed out [2] that $\mathrm{P}(\mathrm{VDF}-\mathrm{TFE})$ copolymer macromolecules can be viewed essentially as PVDF chains with increased content of head-to-head defects.

PVDF and its copolymers are semi-crystalline materials containing crystalline and amorphous phases. The amorphous phase at room temperature is in the liquid-viscous state, since the glass transition temperature $T_{g}$ is about minus $40-50{ }^{\circ} \mathrm{C}$. When melt is cooled, some molecular chains form crystals (lamellae) [3].

The materials are characterized by polymorphism with two basic crystalline $\alpha$ and $\beta$ phases corresponded to two types of the polymer chain conformations [4]. The chains in the $\alpha$-phase crystallites are stacked antiparallel, so that the total dipole moment of the unit volume is zero. Therefore, the $\alpha$-phase is a non-polar phase. The polymer chains in the $\beta$-phase are in the shape of a flat zigzag. All molecular dipoles along the chain are oriented in one direction, and the chains in the crystallites are stacked parallel to each other. As a result, a highly polar $\beta$-phase with spontaneous ferroelectric polarization of $P_{o}=130 \mathrm{mC} / \mathrm{m}^{2}$ is formed. The direction of the polarization vector, as in any ferroelectric material, 
can be changed under action of the external electric field. The ratio between $\alpha$-phase and $\beta$-phase depends on composition of the polymer and on its treatment. [4].

PVDF crystallizes from the melt forming the nonpolar $\alpha$-phase. To obtain the ferroelectric $\beta$-phase in PVDF crystallites, uniaxial or biaxial stretching is performed, after which a significant part of the $\alpha$-phase (but not all) is converted to the polar $\beta$-phase [4]. Copolymers, unlike of PVDF, immediately form the $\beta$ phase during crystallization from the melt. The orientation stretching is also used sometimes, but only to increase content of the $\beta$-phase and to increase crystallinity up to $90 \%$ and higher, while the crystallinity of PVDF is of the order of $50 \%$, and it cannot be increased by a subsequent processing. Disadvantages of the copolymers are the complex technology of their preparation and dependence of the Curie temperature on the composition. In PVDF, the Curie temperature is not experimentally determined, because it is above the melting point $\left(>180{ }^{\circ} \mathrm{C}\right)[4]$.

The most studied is the $\mathrm{P}(\mathrm{VDF}-\mathrm{TrFE})$ copolymer [57], while only a few studies were devoted to the properties of such an attractive ferroelectric polymer as P(VDF-TFE) [8-16]. Thus, the fundamental properties of $\mathrm{P}(\mathrm{VDF}-\mathrm{TFE})$ have not been fully investigated.

That is why our task was to study the features of formation and relaxation of the polarized state in P(VDFTFE) copolymer, as well as unusual properties of the ferroelectric polarization switching comparing with those of pure PVDF. In this work, we systematically investigate the switching dynamics of P(VDF-TFE) films in an unprecedentedly wide range of switching voltage pulse duration from $10 \mu \mathrm{s}$ to $100 \mathrm{~s}$. We also study relaxation of the polarization with time by comparing thermally stimulated depolarization currents of freshly poled samples and the samples stored after poling for 14 months.

\section{Experimental part}

Samples were taken from an experimental grade random $\mathrm{P}(\mathrm{VDF}-\mathrm{TFE})$ copolymer $20 \mu \mathrm{m}$ thick film composed of $94 \%$ of VDF and $6 \%$ of TFE. The film had been extruded from melt and uniaxially stretched by the supplier (Plastpolymer, Russia). The crystallographic structure of the polymer under study exhibited $95 \%$ of crystalline phase and $5 \%$ of amorphous phase.

IR spectra of PVDF and P(VDF-TFE) films are shown in Fig. 1. Typical for $\alpha$-phase peaks at wave numbers of 532 and $614 \mathrm{~cm}^{-1}$ [17] are clearly seen in the IR spectrum of PVDF, but they are absent or very small in the case of $\mathrm{P}(\mathrm{VDF}-\mathrm{TFE})$ indicating that the copolymer consists mainly of the ferroelectric $\beta$-phase crystallites. Detailed calculations revealed that the fraction of the ferroelectric $\beta$-phase in relation to the non-polar $\alpha$-phase in P(VDF-TFE) films corresponded to a ratio of 90:10. The IR measurements on poled samples had shown that the interrelation between $\alpha$ and $\beta$ phases remained unchanged after poling and switching of polarization.

$\mathrm{Al}$ or Au electrodes of $0.2 \mathrm{~cm}^{2}$ areas were deposited on both sides of the film by either vacuum evaporation, or cathode sputtering. Poling and switching experiments have been performed at the Electronic Material Properties Division of the Darmstadt Technological University utilizing the electrical circuit described elsewhere [18] and shown in Fig. 2.

The DC voltage was supplied by a conventional high voltage source buffered by a $0.5 \mu \mathrm{F}$ high-voltage capacitor large enough to support the required poling and switching currents. Actual high voltage poling and polarization switching were performed by means of an electronic high voltage / high current push-pull switch from Behlke Germany. It was possible to apply voltage pulses from 100 ns to $1000 \mathrm{~s}$ duration controlled by a remote low-voltage pulse generator.

The measuring branch consisted of a sample having apparent capacitance of about $C_{s}=107 \mathrm{pF}$ at $100 \mathrm{~V}$, a current limiting resistor $R=1 \mathrm{k} \Omega$ and a series measuring capacitor $C_{o}=0.2 \mu \mathrm{F}$. The voltage drop at the capacitor $C_{o}$ was registered by means of the Tektronix TDS 510A oscilloscope connected through a high impedance operational amplifier $\left(R_{i n}=10^{13} \Omega\right)$. Leakage of charges from the probe capacitor $C_{o}$ to ground due to parasitic currents were tested and found to be negligible for the utilized measuring times.

The voltage at the series capacitor $C_{o}$ was used to calculate the charge flowing through the sample during initial poling, short circuiting and polarization switching. The total "apparent" displacement $D_{l}$ included not only the ferroelectric polarization current, but also a reversible capacitive current and the leakage current due to non-zero conductivity of the sample. After each switching and shutdown in the short-circuited state, re-poling called "forward poling" was performed in the direction of switching. The corresponding displacement curves $D_{2}$ contained all components of $D_{l}$ except for the switched ferroelectric polarization. Therefore, the average ferroelectric polarization $P_{m}$ was calculated as the difference between $D_{1}$ and $D_{2}$. More details on processing experimental $D_{1}$ and $D_{2}$ curves can be found in [19].

In the mode of measuring the charging current, the calibrated measuring resistance $R_{o}=50 \Omega$ (Fig. 2) was connected in series with the sample instead of the measuring capacitor $C_{o}$. In this case, the voltage drop at $R_{o}$ was proportional to the charging current.

To guarantee the uniform distribution of the ferroelectric polarization in the thickness direction of $\mathrm{P}(\mathrm{VDF}-\mathrm{TFE})$ films, we performed initial poling of a virgin non-polarized sample by applying DC voltage of $V_{l}=3.2 \mathrm{kV}\left(E_{l}=160 \mathrm{MV} / \mathrm{m}\right)$ during $50 \mathrm{~s}$ with subsequent short-circuiting for $15 \mathrm{~min}[14,21] .160 \mathrm{MV} / \mathrm{m}$ can be considered as the highest working field for P(VDF-TFE) films, because the electrical breakdown often occurs at higher fields.

After each switching, the fully polarized state was restored (conditioning) and, the corresponding pulse of the same duration was again applied without changing the voltage polarity. The displacements difference in the first and the second cases $\left(D_{1}-D_{2}\right)$ gave the kinetics of the ferroelectric polarization switching [18, 19].

The sequence of switching and conditioning experiments is shown in Fig. 3.

After initial poling $(P)$ and short circuiting, DC voltage of $V_{2}=2.8 \mathrm{kV}\left(E_{2}=140 \mathrm{MV} / \mathrm{m}\right)$ was applied for $\tau_{l}=5 \mu \mathrm{s}$. The experiment was called "forward poling" 
$\left(F P_{l}\right)[18,19]$. Then the first switching voltage pulse of $V_{2}=2.8 \mathrm{kV}\left(S w_{1}\right)$ was applied for $\tau_{1}=5 \mu \mathrm{s}$. After polarization switching and short circuiting, the sample was conditioned $(C)$ to restore its fully polarized state before performing the second forward poling $\left(\mathrm{FP}_{2}\right)$ and switching at $\tau_{2}=50 \mu \mathrm{s}\left(S w_{2}\right)$. Parameters of the conditioning was the same as during initial poling $\left(V_{l}=3.2 \mathrm{kV}, E_{l}=160 \mathrm{MV} / \mathrm{m}\right)$. The described process was continued for studying switching by application of longer pulses $\left(\tau_{3}=0.5 \mathrm{~ms}, \tau_{4}=5 \mathrm{~ms}\right.$, and $\left.\tau_{5}=50 \mathrm{~ms}\right)$. Further increase of the pulse duration did not make sense, because the value of the switched ferroelectric polarization, as seen in Fig. 4, already reached saturation and remained constant.

For studying the thermally stimulated depolarization (TSD) currents in poled P(VDF-TFE), the same films

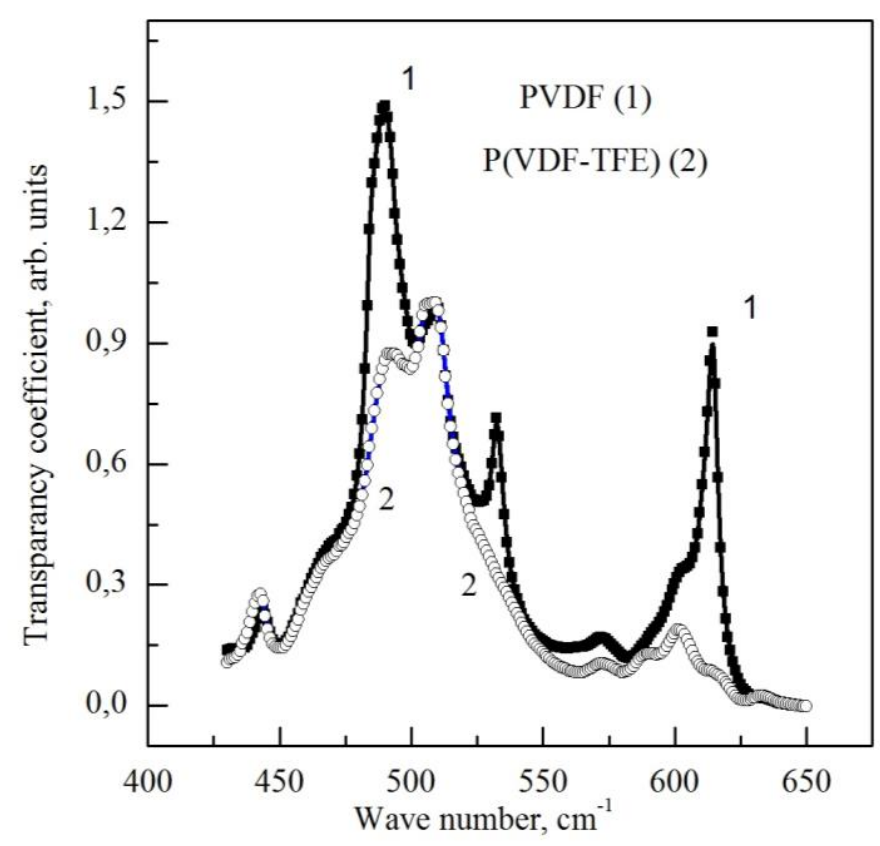

Fig. 1. FT infrared spectra of PVDF and P(VDF-TFE).

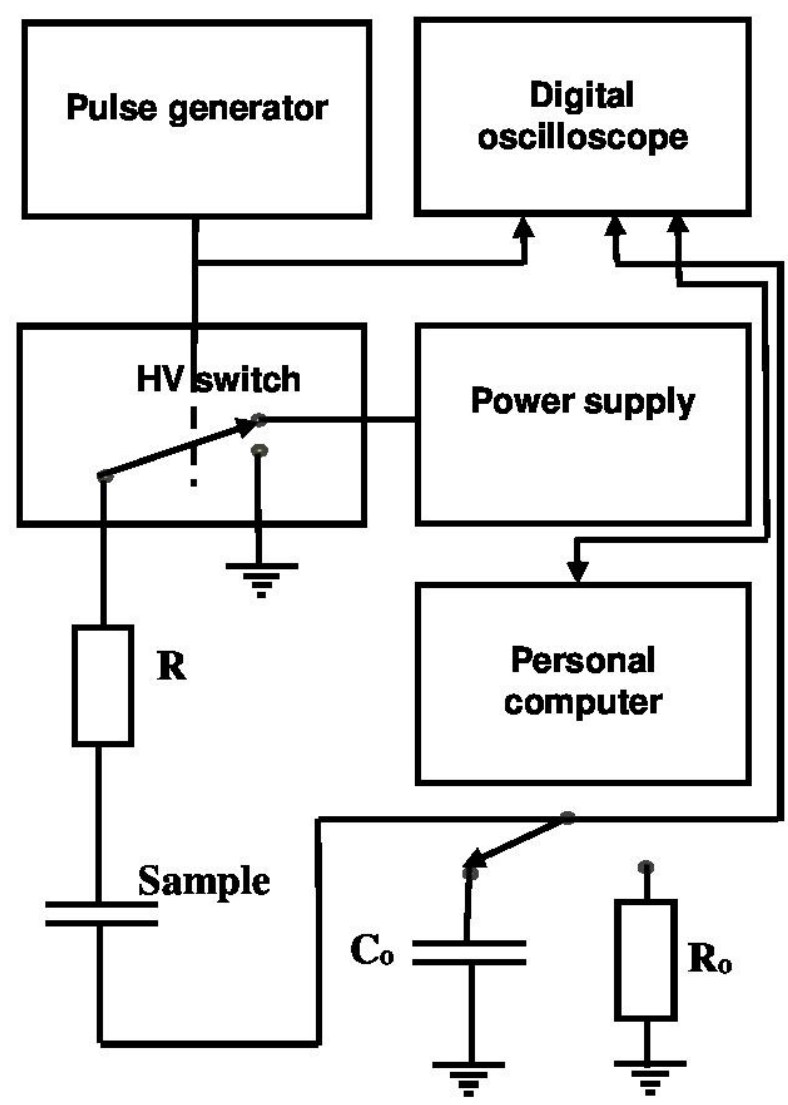

Fig. 2. Block-diagram of the set-up for poling of P(VDF-TFE) films and polarization switching. 


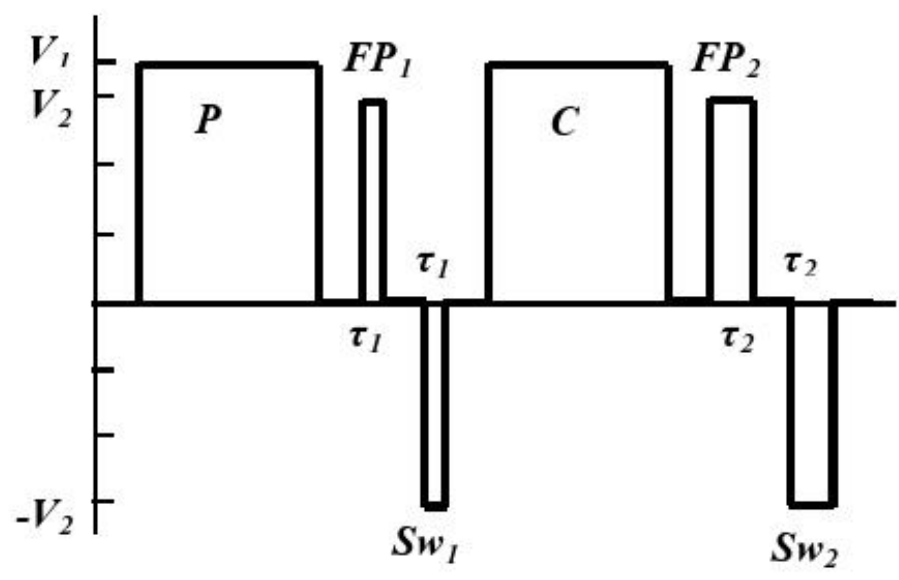

Fig. 3. Diagram of operations sequence for obtaining data on polarization switching presented in Fig. 4.

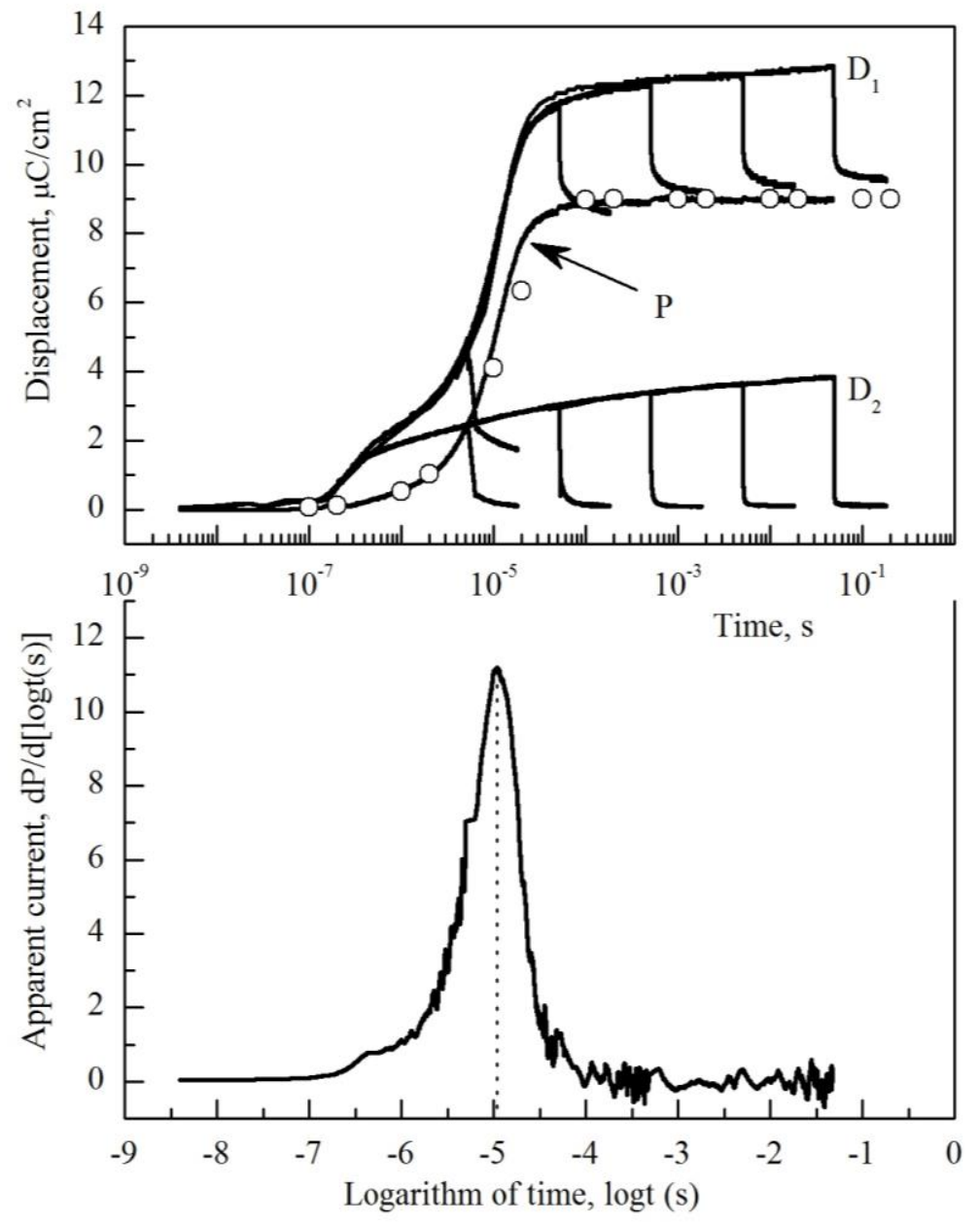

Fig. 4. The upper graph shows kinetics of the total electric displacement $\left(D_{1}\right)$, the unstable polarization and conductivity component $\left(\mathrm{D}_{2}\right)$ and the ferroelectric polarization. Polarization switching was performed in the field of $140 \mathrm{MV} / \mathrm{m}$. The lower graph shows derivative of the ferroelectric polarization curve $\mathrm{P}$ on the upper graph illustrating the shape and position of the switching current curve.

have been used, but processing of the films was different. $\mathrm{Al}$ electrodes of $20 \mathrm{~mm}$ diameter and $150 \mathrm{~nm}$ thick were deposited only on one side of the samples by the thermal evaporation in vacuum. Poling was performed by using a corona triode [20] with the bare surface of the sample exposed to a negative corona initiated by a pointed tungsten electrode. Ions and electrons passed through the control grid kept at a constant negative potential with respect to the grounded aluminium rear electrode. The poling field was created by charges adsorbed on the surface of the sample. The grid was made vibrating to allow simultaneous measurement of the apparent surface 
(electret) potential by Kelvin's method and the poling current.

Constant voltage corona poling was performed at elevated temperature of $80-100{ }^{\circ} \mathrm{C}$. The samples were cooled down after poling to room temperature under the applied field. TSD currents were measured at the heating rate of $4 \mathrm{~K} / \mathrm{min}$ in the open circuit mode with a $25 \mu \mathrm{m}$ thick FEP-Teflon spacer used as a dielectric gap. A number of samples were stored after poling for 14 months and then TSD measurements have been repeated.

\section{Results and discussion}

The total displacement curve $D_{l}(t)$ experimentally measured by the capacitive method during the polarization reversal (Fig. 4) contains three components: the irreversible ferroelectric polarization switching component $D_{f e r}(t)$, the reversible capacitive component $D_{\text {cap }}(t)$, and the contribution caused by the explicit nonzero conductivity of the sample $D_{\text {cond }}(t)$ [19]:

$$
D_{1}(t)=D_{\text {cap }}(t)+D_{\text {fer }}(t)+D_{\text {cond }}(t)
$$

The following phenomenological formula for the electric $D_{l}(t)$ displacement during the polarization switching was proposed by Furukawa in his fundamental study on P(VDF-TrFE) copolymer [22]:

$$
D_{1}(t)=\varepsilon_{o} \varepsilon E+2 P_{r}\left[1-\exp \left(-\frac{t}{\tau_{s}}\right)^{n}\right]+g E t
$$

where $\varepsilon_{o}$ is the permittivity of a vacuum, $\varepsilon$ is the dielectric constant of the film, $2 P_{r}$ is the amount of reversed polarization equal to double the remnant polarization $P_{r}$ at the applied field $E, \tau_{s}$ is the switching time, i.e. the time at which $\partial D_{f e r} / \partial \operatorname{logt}$ becomes a maximum, $n$ is approximately the half width of $\partial D_{\text {fer }} / \partial$ logt peak measured in decades, and $g$ is the DC conductivity of the sample.

The measured value of the displacement $D_{2}(t)$ during forward poling contains only contributions of capacitive and conductive components:

$$
D_{2}(t)=\varepsilon_{o} \varepsilon E+g E t=E\left(\varepsilon_{o} \varepsilon+g t\right),
$$

Thus, dependence of the switched ferroelectric polarization on time can be calculated as

$$
P(t)=D_{f e r}(t)=D_{1}(t)-D_{2}(t)=2 P_{r}\left[1-\exp \left(-\frac{t}{\tau_{s}}\right)^{n}\right],
$$

Furukawa [22] suggested to present displacement and polarization curves as functions of $\log t$. Experimental curves $D_{1}(\log t)$ and $D_{2}(\log t)$, as well as calculated function $P(\log t)$ are shown in the upper part of Fig. 4. By differentiating the polarization switching curve $P(\log t)$, we obtained the apparent switching current density

$$
j_{\text {app }}(t)=\frac{\partial P}{\partial \log t},
$$

We call $j_{a p p}(t)$ the "apparent" current density, because the real switching current density is different, namely

$$
j(t)=\frac{\partial P}{\partial t},
$$

The $j_{a p p}(t)$ graph is shown in the lower part of the Fig. 4. A maximum of the $j_{\text {app }}(t)$ corresponds to $\log \tau_{s} \approx-5$. Therefore, the time $\tau_{s}$ called "the polarization switching time" is equal to $\tau_{s} \approx 10 \mu \mathrm{s}$.

The values of $P_{r}=6.5 \mu \mathrm{C} / \mathrm{cm}^{2}, \tau_{s}=10 \mu \mathrm{s}, n=0.67$ were determined as best-fit parameters during a fitting procedure. Capacitive and conductive components of $D_{2}(t)$ should be separated for finding the dielectric constant $\varepsilon$ and the conductivity $g$. This can be done by processing experimentally measured values of $D_{2}\left(t_{1}\right)$ and $D_{2}\left(t_{2}\right)$ shown in Fig. 4.

The sample was short-circuited for $50 \mathrm{~ms}$ after the polarization switching. The measured decay of displacement $\Delta D_{l}=3.71 \mu \mathrm{C} / \mathrm{cm}^{2}$ was due to discharge of the sample capacitance. Thus, $\Delta D_{1}=\varepsilon_{o} \varepsilon E$ from where $\varepsilon \approx 30$. The measured value of $\Delta D_{2}=3.75 \mu \mathrm{C} / \mathrm{cm}^{2}$. It is obvious that the difference $\Delta D_{1^{-}}-\Delta D_{2}$ is the contribution of conductivity. Therefore, $\Delta D_{1}-\Delta D_{2}=g E t$ from where $g=5.7 \cdot 10^{-11} \mathrm{~S} / \mathrm{m}$.

It is known that the stationary value of $\varepsilon$ in PVDF and its copolymers is $10-12$, but $\varepsilon$ increases during the polarization switching to about 30 [22]. So, obtained here value of $\varepsilon$ is in good agreement with published data. As for values of conductivity $g$, the data are very limited. Reported in $[23,24] g=1.510^{-12} \mathrm{~S} / \mathrm{m}$ for PVDF is of the same order of magnitude as found by us for P(VDFTFE).

The switching time $\tau_{s}$ of many ferroelectrics including PVDF and its copolymers depends upon the applied field $E$ according to the exponential law [22, 25]

$$
\tau_{s}=\tau_{s o} \exp \left(\frac{E_{a}}{E}\right)
$$

where the pre-exponential factor (limiting switching time) $\tau_{s o}$ and the activation field $E_{a}$ are constants depended on the material, but not having a physical meaning. To find values of $\tau_{s o}$ and $E_{a}$ in the studied $\mathrm{P}$ (VDF-TFE) copolymer, we performed the polarization switching at three different fields and obtained $\tau_{s 1}=$ $2.34 \mu \mathrm{s}$ at $E_{1}=160 \mathrm{MV} / \mathrm{m}, \tau_{s 2}=5 \mu \mathrm{s}$ at $E_{2}=140 \mathrm{MV} / \mathrm{m}$, and $\tau_{s 3}=12.8 \mu \mathrm{s}$ at $E_{3}=120 \mathrm{MV} / \mathrm{m}$ by direct measurement of the switching polarization current. Then the average values of $E_{a}$ and $\tau_{s o}$ were calculated by solving corresponding equations. It appeared that $E_{a}=$ $360 \pm 10 \mathrm{MV} / \mathrm{m}$ and $\tau_{s o}=14.3 \pm 2.4 \mathrm{~ns}$ with the confidence level of 0.9. These data for P(VDF-TFE) copolymer were obtained for the first time. Furukawa [22] reported $\tau_{s o}=10 \mathrm{~ns}$ and $E_{a}=(0.75-1.0) \mathrm{MV} / \mathrm{m}$ for $\mathrm{P}(\mathrm{VDF}-\mathrm{TrFE})$ copolymer. We have not found in literature corresponding data for pure PVDF. However, considering very similar dependencies $\log \tau_{s}=\mathrm{f}(\log E)$ for PVDF and its copolymers [22] one can assume that $\tau_{s o}$ and $E_{a}$ in PVDF are of the same order.

Polarization switching processes in the copolymer occur during a very short time. So, it is difficult to resolve them by the capacitive method. Therefore, to study initial stages of poling and polarization reversal, we also used the method of the current flowing through the measuring resistor connected in series with the sample (Fig. 2). Experimentally measured current in the first $20 \mu \mathrm{s}$ of the switching voltage $V=2.8 \mathrm{kV}$ application $(E=140 \mathrm{MV} / \mathrm{m})$ is shown in Fig. 5. As one can see, the total current curve contains a weak maximum. After subtracting the exponentially decaying capacitive current from the total current, we obtained the 

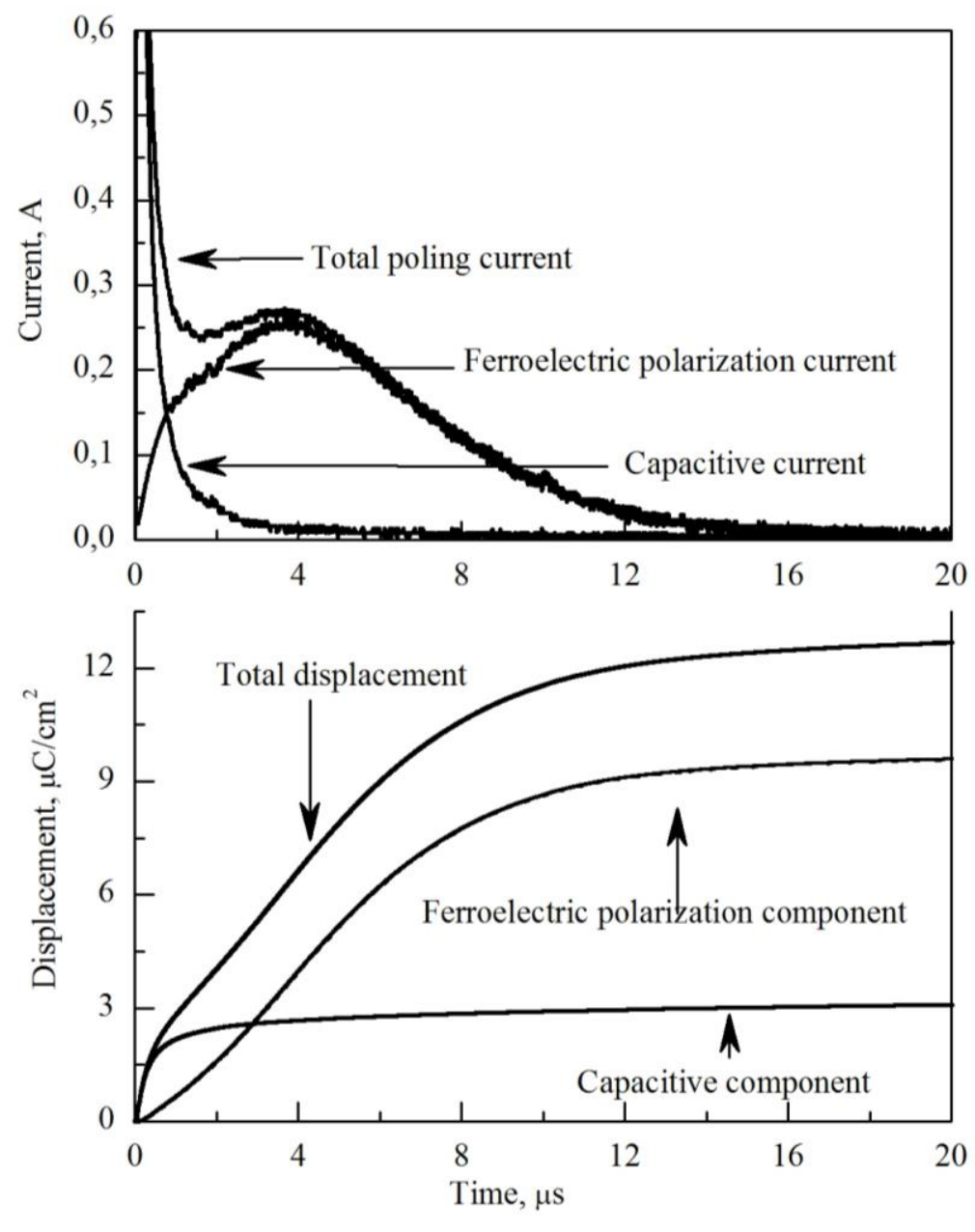

Fig. 5. Switching currents in $\mathrm{P}(\mathrm{VDF}-\mathrm{TFE})$ during application of DC voltage pulses ( $E=140 \mathrm{MV} / \mathrm{m})$ : the total current, the capacitive current component, and the current responsible for the ferroelectric polarization switching.

The lower part shows total displacement, as well as its ferroelectric polarization and capacitive components obtained by integrating the curves of the upper part.

polarization switching current. The contribution of conductivity can be neglected during the first microseconds of the switching voltage application, because Maxwell's relaxation time characterizing movement of the conductivity charges at $\varepsilon=30$ and $g=5.7 \cdot 10^{-11} \mathrm{~S} / \mathrm{m}$ is equal to $\tau_{M}=\varepsilon_{o} \varepsilon / g=4.7 \mathrm{~s}$, being more than 200 thousand times larger than the time of the experiment (Fig. 5). As one can see, the polarization current obtained by subtracting the capacitive current from the total current has a maximum at about $3.75 \mu \mathrm{s}$. Namely this value should be considered as the polarization switching time in $\mathrm{P}$ (VDF-TFE).

By integrating the current curves we obtained curves of the total displacement, capacitive component and the ferroelectric polarization switching component. These curves are shown in the lower part of Fig. 5. Comparison of data shown in Fig. 4 and 5 with the corresponding data on PVDF $[18,19,23]$ allows us to draw the following conclusions:

1. The value of the switched polarization in P(VDF-
TFE) under action of the switching voltage for $0.1 \mathrm{~s}\left(2 P_{r}\right.$ $=13 \mu \mathrm{C} / \mathrm{cm}^{2}$ at $E=140 \mathrm{MV} / \mathrm{m}$ ) is very close to that in the case of PVDF.

2. Almost complete polarization switching in $\mathrm{P}\left(\right.$ VDF-TFE) takes about $10^{-4} \mathrm{~s}$ (Fig. 4), while switching in PVDF occurs smoothly and the saturation is not observed even after $100 \mathrm{~s}$ of the voltage application $[18,19]$.

3. Displacement plots in the case of the copolymer are almost rectangular in shape (Fig. 4) indicating absence of the unstable part of the dipole polarization, the presence of which is typical for PVDF.

These features can be explained by the higher crystallinity of $\mathrm{P}(\mathrm{VDF}-\mathrm{TFE})$ films $(95 \%)$ comparing to PVDF $(50 \%)$. Existence of the amorphous phase in PVDF makes difficult compensation of the depolarizing field in crystallites by trapped charges. In general, the behaviour of the copolymer is close to the behaviour of ceramic ferroelectrics. 
Several series of experiments were carried out for getting more complete picture of the polarization switching. Based on measurements at various fields and times of the field application, the graphs in Fig. 6 illustrate the dependence of the switched polarization on the field strength at different duration of the switching voltage pulse. Comparison with the corresponding dependences for PVDF shows that the coercive field in
$\mathrm{P}(\mathrm{VDF}-\mathrm{TFE})$ has the same order of magnitude as in PVDF (about $50 \mathrm{MV} / \mathrm{m}$ ).

The obtained results (Fig. 6) have practical importance because they allow one to select switching options. For example, the application of electric fields below $60 \mathrm{MV} / \mathrm{m}$ is inappropriate, because the switched polarization is very small. At the same time, when electric field exceeding $120 \mathrm{MV} / \mathrm{m}$ is used, the switching

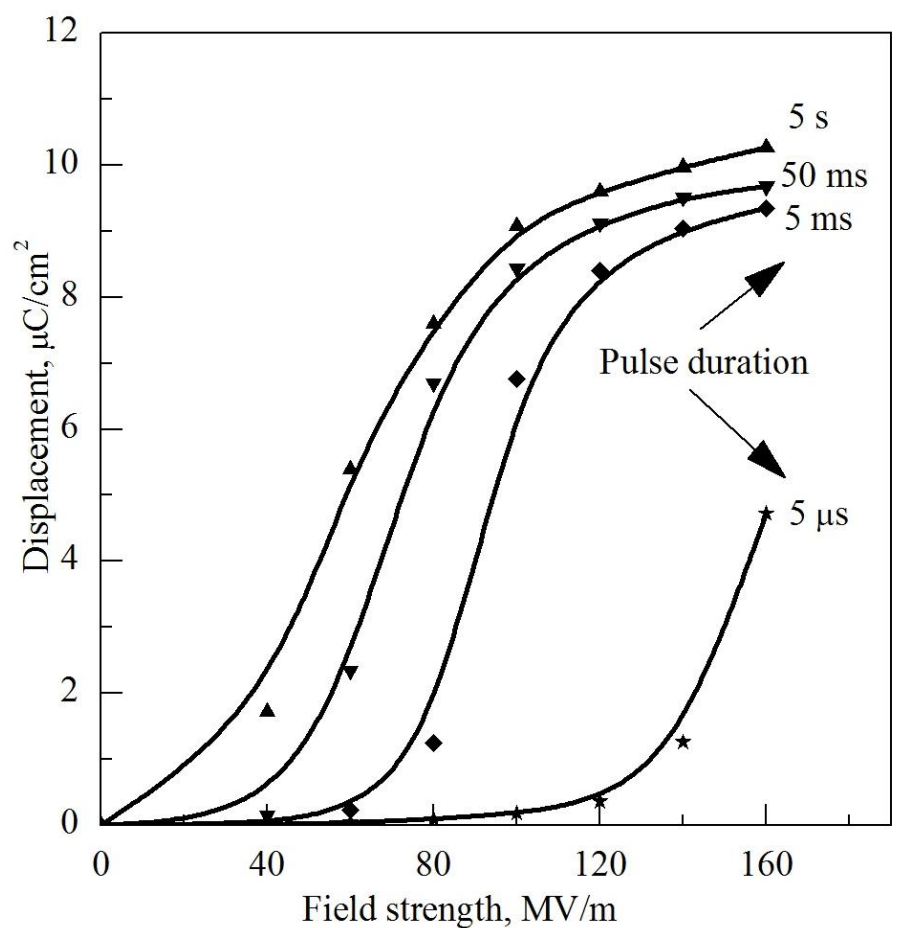

Fig. 6. Dependence of the switched polarization in P(VDF-TFE) on the applied field strength at different duration of the switching voltage pulses.

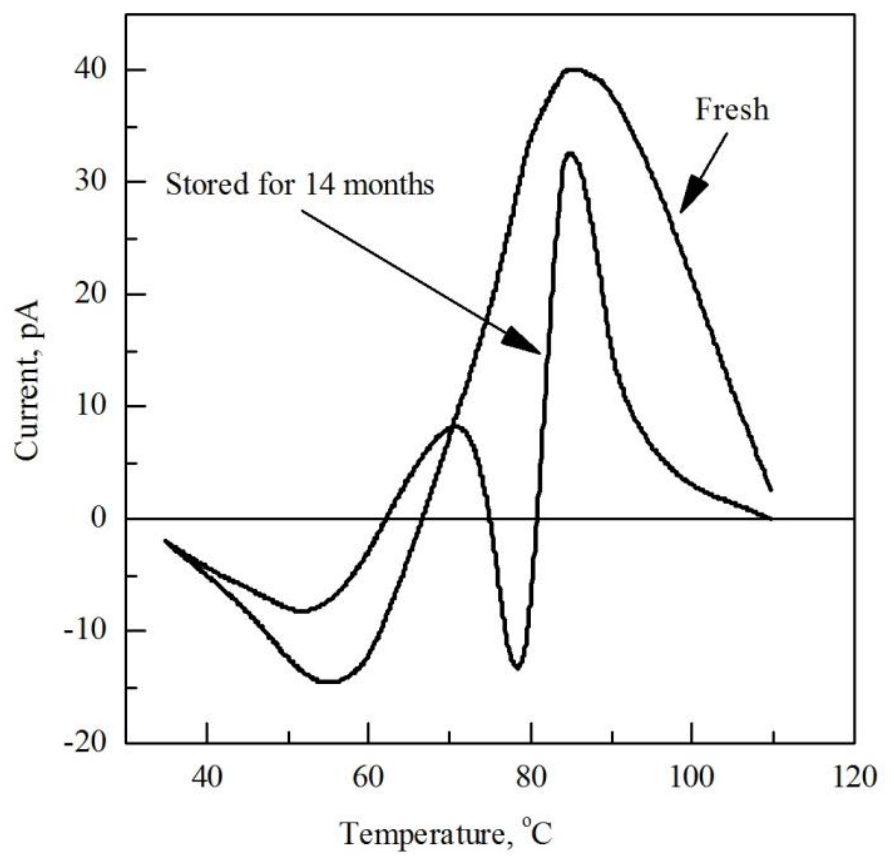

Fig. 7. Thermally Stimulated Depolarization currents of P(VDF-TFE) films 1 hour after corona poling and after 14 months of storage in the short-circuited condition. 
occurs very quickly and there is no significant difference in application of $5 \mathrm{~ms}, 50 \mathrm{~ms}$ or even $5 \mathrm{~s}$ pulses.

Ferroelectric polymers including P(VDF-TFE) are essentially two-component materials consisting of ferroelectric crystallites and polar amorphous phase, in which polarization can be formed and relaxed like in any polar electret. a powerful technique for studying relaxation processes in polymer electrets is the thermally stimulated depolarization (TSD). Although a theory of the TSD method was developed only for thermally frozen Debye processes, it has been also used to study relaxation in ferroelectric polymers. In this paper we measured TSD currents in poled P(VDF-TFE) in order to find interrelation between ferroelectric and electret polarization.

Each sample was cut in two equal pieces after initial poling. One set of halves was studied shortly after completion of poling, while another one was stored for 14 months before TSD measurements. Two oppositely directed TSD peaks are seen in fresh samples (Fig. 7), while four peaks or two pairs of the oppositely directed peaks were found in the samples stored for a long time. To explain this new phenomenon, we assume that two peaks in the fresh samples are the result of superposition of two overlapped and oppositely directed peaks, of which one is caused by relaxation of the ferroelectric polarization and another by relaxation of the polarization in the amorphous phase. The less thermally stable pair of peaks in the stored samples seems to be related to the electret component of polarization concentrated in the amorphous phase. Then the second, more thermally stable pair of relaxation processes, corresponds to the ferroelectric polarization in crystallites and to the trapped charges compensating the depolarizing field [18, 19].

It follows from our results that very slow redistribution of charges and polarization takes place after completion of poling until the electret and ferroelectric components of polarization are finally separated, both accompanied by the compensating trapped charges. In order to obtain high and stable polarization, it is necessary to remove the unstable electret component of polarization. In the case of $\mathrm{P}(\mathrm{VDF}-$ TFE) it was sufficient to heat poled sample to $60{ }^{\circ} \mathrm{C}$. It came out that the first pair of the TSD peaks disappeared in the stored films. The procedure may not be the same for other ferroelectric polymers.

\section{Conclusions}

In this paper we presented results of experimental studies of P(VDF-TFE) ferroelectric polymer films in comparison with similar studies of pure PVDF. It has been found that amounts of the switchable polarization in $\mathrm{P}(\mathrm{VDF}-\mathrm{TFE})$ and in PVDF are almost the same. The coercive fields are also very similar $(\approx 50 \mathrm{MV} / \mathrm{m})$. However, complete switching in P(VDF-TFE) is very fast $(0.1 \mathrm{~ms})$, while switching in PVDF is not completed even after $100 \mathrm{~s}$ of voltage application. Displacement plots in copolymer are rectangular indicating absence of the unstable component of the ferroelectric polarization typical for PVDF. Thus, the P(VDF-TFE) films are more appropriate for practical application in sensors and actuators where the actuation time is important.

The obtained results allowed determining the best range of applied electric fields $(60-120 \mathrm{MV} / \mathrm{m})$ and proper time of its application $(5 \mathrm{~ms})$. It appeared from the results of the TSD studies that electret and ferroelectric components of polarization are separated with time after poling. It was shown that heating of the poled P(VDFTFE) films to $60{ }^{\circ} \mathrm{C}$ is sufficient for removing the unstable electret component of polarization.

Fedosov S. - Doctor of Sciences (Physics \& Mathematics), Professor of the Physics \& Mathematics Department;

Sergeeva A. - Doctor of Sciences (Physics \& Mathematics), Professor, Head of the Physics \& Mathematics Department.

[1]. W. Xia, Z. Zhang, IET Nanodielectrics 1(1), 17 (2018) (https://doi.org/10.1049/iet-nde.2018.0001).

[2]. J. Lando, W. Doll, J. Macromol. Sci. B, 2(2), 205 (1968) (https://doi.org/10.1080/00222346808212449).

[3]. J. F. Legrand, IEEE Trans. Electr. Insul. 28, 336 (1993) (https://doi.org/10.1109/14.236214).

[4]. M. E. Lines, A. M. Glass, Principles and Applications of Ferroelectrics and Related Materials (Oxford University Press, Oxford, 2001).

[5]. D. Mao, B. E. Gnade, M.A. Quevedo-Lopez, Ferroelectric Properties and Polarization Switching Kinetic of Poly (vinylidene Fluoride-trifluoroethylene) Copolymer (INTECH Open Access Publisher, 2011).

[6]. Y. Mabuchi, T. Nakajima, T. Furukawa, et al, App. Phys. Exp. 4(7), 071501 (2011) (https://doi.org/10.1143/APEX.4.071501).

[7]. W. J. Hu, D.-M. Juo, L. You, et al, Scientific Reports 4, 4772 (2014) (https://doi.org/10.1038/srep04772).

[8]. J. M. Carr, M. Mackey, L. Flandin, et al, Polymer 54, 1679 (2013) (https://doi.org/10.1016/j.polymer.2013.01.037).

[9]. Z. Xia, S. Fedosov, A. Sergeeva, H. Zhang, 9th Intern. Symp. Electrets (Tongji, Shanghai, 1996), p. 902-907.

[10]. Q. Liu, I. Khatri, R. Ishikawa, et al, Appl. Phys. Lett. 103, 163503 (2013) (https://doi.org/10.1063/1.4826323).

[11]. B. Kussner, G. Eberle, W. Eisenmenger, S.N. Fedosov, A.E. Sergeeva, J. Mater. Sci. Lett. 16, 368 (1997).

[12]. V. Kochervinskii, I. Malyshkina, A. et al, J. Appl. Phys. 117(21), 214101 (2015) (https://doi.org/10.1063/1.4921851).

[13]. H. Yamada, T. Fukushima, T. Yoshimura, et al, Jpn. J. Appl. Phys. 50, 09NA06 (2011) (https://doi.org/10.1143/JJAP.50.09NA06). 
[14]. S. N. Fedosov, A. E. Sergeeva, G. Eberle, W. Eisenmenger, J. Phys. D: Appl. Phys. 29(12), 3122 (1996) (https://doi.org/10.1088/0022-3727/29/12/028).

[15]. Y. Nakagawa, Y. Hashizume, T. Nakajima, et al, Jpn. J. Appl. Phys. 55, 10TA12 (2016) (https://doi.org/10.7567/JJAP.55.10TA12).

[16]. T. Kanashima, Y. Katsura, M. Okuyama, Jpn. J. Appl. Phys. 53, 04ED11 (2014) (https://doi.org/10.7567/JJAP.53.04ED11).

[17]. A. H. Kuptsov G. N. Zhizhin, Handbook of Fourier Transform Raman and Infrared Spectra of Polymers (Elsevier Science, 1998).

[18]. H von Seggern, S. N. Fedosov, Appl. Physics Letters, 91(6), 62914 (2007) (https://doi.org/10.1063/1.2769402).

[19]. S. Fedosov, H. von Seggern, J. Nano-Electron. Phys., 5(4), 04056 (9 pp) (2013).

[20]. J. A. Giacometti, S. Fedosov, M. M. Costa, Brazilian Journal of Physics, 29(2) 269 (1999).

[21]. S. N. Fedosov, A. E. Sergeeva, J. Nano-Electron. Phys., 11(1) 01012-1(7 pp.) (2019) (https://doi.org/10.21272/jnep.11(1).01012).

[22]. T. Furukawa, Phase transitions, 18, 143, 1989 (https://doi.org/10.1080/01411598908206863).

[23]. H. von Seggern, S. Fedosov, IEEE Trans. Dielectr. Electr. Insul., 11(2) 232 (2004) (https://doi.org/10.1109/TDEI.2004.1285892).

[24]. S. N. Fedosov, H. von Seggern, J. Appl. Phys. 103(1), 014105 (2008) (https://doi.org/10.1063/1.2824940).

[25]. H. Ishii, T. Nakajima, T. Furukawa, S. Okamura, Japanese Journal of Applied Physics 52 041603(2013) (https://doi.org/10.7567/JJAP.52.041603).

\title{
С.Н. Федосов, О.Є. Сергєєва
}

\section{Тонкі плівки сополімеру вініліденфториду з тетрафторетиленом: динаміка перемикання фероелектричної поляризації}

\author{
Одеська національна академія харчових технологій, Одеса, Украӥна, snfedosov@ukr.net
}

\begin{abstract}
Сополімер вініліденфториду 3 тетрафторетиленом П(ВДФ-ТФЕ) $\epsilon$ типовим фероелектричним полімером, який до цього часу не був достатньо детально досліджений у порівнянні 3 полівініліденфторидом (ПВДФ) та його сополімером П(ВДФ-ТрФЕ). Метою даної роботи було розкриття особливостей формування фероелектричної поляризації та ії перемикання в тонких плівках П(ВДФ-ТФЕ) в різних умовах, таких як величина прикладеного електричного поля та тривалість його дії в межах 8 порядків від 10 мкс до 100 с. Застосована нами послідовність імпульсів напруги при електризації та перемиканні поляризації дала змогу виявити характеристики динаміки перемикання поляризації. Для збільшення роздільної здатності вимірювань були використані два методи реєстрації електричної індукції, які доповнювали один одного. Особливості релаксації поляризації та просторового заряду вивчалися методом термічно стимульованої деполяризації. Спостерігалося нове явище поступового відокремлення процесів релаксації, які пов'язані з поляризацією та просторовим зарядом. Обидва процеси супроводжувалися наявністю захопленого заряду, який компенсував деполяризуюче поле. Було сформульовано кілька практичних рекомендацій щодо бажаних значень параметрів електризації плівок та їх додаткової обробки для підвищення стабільності величини фероелектричної поляризації.

Ключові слова: сегнетоелектрики, сегнетоелектричні полімери, PVDF, P (VDF-TFE), поляризація, електрики, космічний заряд, термостимульована деполяризація.
\end{abstract}

